\title{
Formas de aplicação de nitrogênio em três cultivares de girassol na savana de Roraima ${ }^{1}$
}

\author{
Different ways of nitrogen placements in three cultivars of sunflower in the savannah \\ of Roraima
}

\author{
Maria Elena Almeida Ivanoff ${ }^{2 *}$, Sandra Cátia Pereira Uchôa ${ }^{3}$, José Maria Arcanjo Alves ${ }^{4}$, Oscar José Smiderle ${ }^{5}$ \\ e Tocio Sediyama ${ }^{6}$
}

\begin{abstract}
Resumo - O nitrogênio é o nutriente que mais limita a produção na cultura do girassol (Helianthus annuus L). A exigência entre cultivares da mesma espécie é distinta, mesmo sob as mesmas condições de cultivo. Objetivando avaliar quatro formas de aplicação do nitrogênio nos componentes de produção de três cultivares de girassol, foi realizado um experimento em delineamento de blocos casualizados em esquema fatorial $(3 \times 4)$, com quatro repetições. Os tratamentos consistiram da combinação de três cultivares de girassol: Agrobel 960, Agrobel 962 e Embrapa 122/V2000 e quatro formas de aplicação da dose de $60 \mathrm{~kg} \mathrm{ha}^{-1}$ de N: 100\% aos 20 dias após a semeadura (DAS) - (0-100-0-0); 30\% na semeadura e 70\% aos 20 DAS - (30-70-0-0); 30\% na semeadura, 30\% aos 20 DAS e $40 \%$ aos 40 DAS (30-30-40-0); $20 \%$ na semeadura, 30\% aos 20 DAS, 30\% aos 40 DAS e $20 \%$ aos 60 DAS (20-30-30-20). As variáveis avaliadas foram: altura de plantas, altura do capítulo, diâmetro da haste, diâmetro do capítulo e a produção de aquênios. A forma de aplicação do N (30-70-0-0) determinou os melhores resultados para as variáveis estudadas, mas a forma (30-30-40-0) proporcionou resultados comparáveis ao tratamento (30-70-0-0); $\mathrm{O}$ tratamento onde o $\mathrm{N}$ foi aplicado na forma (20-30-30-20) determinou redução no desempenho do girassol em todas as variáveis estudadas. $\mathrm{O}$ efeito varietal foi observado apenas para altura da planta e altura do capítulo. A produtividade de aquênios alcançada foi de $1.639 \mathrm{~kg} \mathrm{ha}^{-1}$, não havendo superioridade dos híbridos Agrobel 960 e Agrobel 962 em relação à variedade Embrapa 122/V2000.
\end{abstract}

Palavras-chave - Helianthus annuus L. Adubação Nitrogenada. Savana. Plantas-efeito nitrogênio.

\begin{abstract}
Nitrogen is the nutrient that limits most the production in the culture of sunflower (Helianthus annuus L). The nutritional requirements among cultivars of the same species is distinct, under the same conditions of culture and for the same agricultural year. With the objective of evaluating four different ways of nitrogen application in the production components of different genotypes of sunflower, an experiment was carried out in a randomized block design in a $3 \times 4$ factorial scheme (genotypes $\mathrm{x}$ ways of nitrogen applying) with four replicates. The treatments consisted on the combination of three varieties: Agrobel 960, Agrobel 962 and V - 2000 and four different ways of nitrogen application: $100 \%$ at 20 days after sowing (DAS) - (0-100-0-0); 30\% at sowing and $70 \%$ at 20 DAS - (30-70-0-0); $30 \%$ at sowing, $30 \%$ at 20 DAS e $40 \%$ at 40 DAS (30-30-40-0); $20 \%$ at sowing, $30 \%$ at 20 DAS, $30 \%$ at 40 DAS e $20 \%$ at 60 DAS (20-30-30-20). Measured variables were: height of the plant, height of the capitulum, diameter of the stem, diameter of the capitulum and achene yield. The ways of nitrogen application affected all components of yield. The $\mathrm{N}$ formulation (30-70-0-0) has determined the best results for the variables studied, but the form (30-30-40-0) provided results comparable to treatment (30-70$0-0)$; treatments where $\mathrm{N}$ was applied as (20-30-30-20) caused decrease in the performance of sunflower for all variables. The varietal effect was observed only for plant height and height of the capitulum. The highest yield of achene achieved was $1.639 \mathrm{~kg}$ ha- 1 , with no superiority for the hybrids Agrobel 960 and 962 in relation to the variety 122/V2000 Embrapa.
\end{abstract}

Key words - Helianthus annuus L. Nitrogen Placements. Savannah. Plant nitrogen-effect.

\footnotetext{
* Autor para correspondência

${ }^{1}$ Recebido para publicação em 26/10/2009; aprovado em 24/06/2010

Parte da dissertação de Mestrado do primeiro autor, apresentada ao Programa de Pós-Graduação em Agronomia, CCA/UFRR

${ }_{2}^{2}$ Programa de Pós-Graduação em Agronomia com área de concentração em Produção Vegetal, Universidade Federal de Roraima, Boa Vista- RR, Brasil, 69.310-270, lena ivanoff@hotmail.com

${ }^{3}$ Departamento de Solos e Engenharia Agrícola, CCA/UFRR, BR 174, Km 12, s/n, Campus do Cauame, Boa Vista-RR, Brasil, 69.310-270, scpuchoa@gmail.com

${ }^{4}$ Departamento de Fitotecnia, CCA/UFRR, BR 174, Km 12, s/n, Campus do Cauame, Boa Vista-RR, Brasil, 69.310-270, arcanjoalves@oi.com.br ${ }^{5}$ Embrapa Roraima, BR 174, Km 08, Distrito Industrial, Caixa Postal 133, Boa Vista-RR, Brasil, 69.301-970, ojsmider@cpafrr.embrapa.br

${ }^{6}$ Departamento de Fitotecnia, UFV, Av. PH Rolfs, Campus Universitário, Viçosa-MG, Brasil, 36.570-000, t.sediyama@ufv.br
} 


\section{Introdução}

A cultura do girassol, Helianthus annuus L., possui um dos maiores índices de crescimento no mundo. Em 2006 foram plantados 23 milhões de hectares produzindo cerca de 32 milhões de toneladas de sementes (FAO, 2008). No Brasil a área plantada de girassol, em 2006, foi de 69.206 hectares, com rendimento médio de $1.475 \mathrm{~kg} \mathrm{ha}^{-1}$. $\mathrm{Na}$ safra de 2008 houve um incremento para 107.494 ha plantados (IBGE, 2008). Esses números revelam que a atividade vem crescendo devido à busca por novas opções de cultivo e ao aumento da demanda das indústrias por óleo de melhor qualidade e, principalmente, para produção de biocombustíveis. Na Região Norte, o girassol pode ser incluído no sistema de produção das pequenas propriedades por fornecer o óleo e outros produtos de alto valor agregado, tais como: casca e torta com 45 a $50 \%$ de proteína bruta (ACOSTA, 2009).

O nitrogênio $(\mathrm{N})$ desempenha importante função no metabolismo e na nutrição da cultura do girassol, e a sua deficiência causa uma desordem nutricional, sendo que esse nutriente é o que mais limita a sua produção, enquanto seu excesso ocasiona decréscimo na porcentagem de óleo (BISCARO et al., 2008).

Em função de suas transformações no solo, o $\mathrm{N}$ tem gerado muitas controvérsias com relação à sua época de aplicação. Para a cultura do milho, Souza et al. (2001) verificaram que a aplicação do $\mathrm{N}$ em dose única na semeadura mostrou resultados iguais quando o $\mathrm{N}$ foi parcelado ou aplicado em cobertura em diferentes épocas, recomendando, assim, a intensificação de estudos em diferentes ambientes e cultivares.

A aplicação do N, de uma só vez ou parceladamente, pode ser mais ou menos eficiente, dependendo da época da aplicação. Para o milho, aplicações mais tardia do N, duas a três semanas antes da floração, determinaram os melhores rendimentos em grãos, uma vez que o $\mathrm{N}$ é fornecido à planta na época em que sua absorção é máxima (SILVA; SILVA, 2003). Por outro lado, pesquisas indicam que altas concentrações de $\mathrm{N}$ na zona radicular são benéficas para promover o rápido crescimento inicial da planta e o aumento na produtividade de grãos (SILVA et al., 2005a, 2005b). Para a cultura do girassol poucas informações são disponíveis acerca desse manejo, tendo sido relatado aumento em produtividade de aquênios com a utilização do parcelamento da dose de cobertura em 15; 30 e 45 dias após a emergência (BISCARO et al., 2008).

Devido à interação entre genótipo e ambiente, presente nas espécies vegetais torna-se necessária a avaliação contínua de genótipos de girassol, o que tornará possível selecionar e recomendar genótipos adaptados às regiões produtoras, podendo aumentar o sucesso do produtor com a cultura, obtendo maiores produtividades e retornos econômicos. Essas informações são, também, relevantes, pois a maioria das cultivares utilizadas, ou em lançamento, foram desenvolvidas em outros países, com características de solo e clima diferentes (PORTO et al., 2009).

Em Roraima, são poucos os estudos sobre o girassol (SMIDERLE et al., 2005). Para que ocorra o seu estabelecimento é preciso que se detenham conhecimentos nas diversas áreas científicas, sendo relevante o estudo do comportamento de cultivares quanto ao ambiente e ao uso eficiente de $\mathrm{N}$ por meio do seu parcelamento.

Tendo em vista que o parcelamento do nitrogênio pode influenciar na sua eficiência, objetivou-se com este trabalho avaliar o efeito de formas de aplicação do nitrogênio nos componentes de produção de três cultivares de girassol, semeadas em um Latossolo Amarelo distrocoeso de região de savana do estado de Roraima.

\section{Material e métodos}

O experimento foi conduzido durante os meses de janeiro a maio de 2007, na área experimental do Centro de Ciências Agrárias da Universidade Federal de Roraima, localizado no município de Boa Vista - RR, coordenadas geográficas de 252'15,49' ' N e 6042’39,89' W. Segundo a classificação de Köppen, o clima da região é do tipo Awi, com duas estações climáticas bem definidas, uma chuvosa (abril-setembro) e outra seca (outubro-março) (Araújo et al., 2001). A precipitação média anual de $1678 \mathrm{~mm}$, umidade relativa do ar em torno de $70 \%$ e temperaturas mínimas e máximas varia de 20 e $38{ }^{\circ} \mathrm{C}$, sendo a média anual em torno de $27,4{ }^{\circ} \mathrm{C}$.

O solo da área do experimento é classificado em Latossolo Amarelo distrocoeso, e apresentava as seguintes características: $\mathrm{pH}\left(\mathrm{em}_{2} \mathrm{O}\right)=5,4 ; \mathrm{Al}$ trocável $\left(\mathrm{cmol}_{\mathrm{c}} \mathrm{dm}^{-3}\right)=0,08 ; \mathrm{Ca}+\mathrm{Mg}\left(\mathrm{cmol}_{\mathrm{c}} \mathrm{dm}^{-3}\right)=0,77$; P-Mehlich-1 $\left(\mathrm{mg} \mathrm{dm}^{-3}\right)=0,07 ; \mathrm{K}\left(\mathrm{mg} \mathrm{dm}^{-3}\right)=14,84$; Matéria orgânica $=7,9 \mathrm{~g} \mathrm{dm}^{-3} ; \mathrm{H}+\mathrm{Al}\left(\mathrm{cmol}_{\mathrm{c}} \mathrm{dm}^{-3}\right)=1,24$; $\mathrm{V}(\%)=39,5 ; \mathrm{m}(\%)=9,0 ;$ Soma de bases $=0,81\left(\mathrm{cmol}_{\mathrm{c}}\right.$ $\left.\mathrm{dm}^{-3}\right) ; \mathrm{CTCt}=2,1\left(\mathrm{cmol}_{\mathrm{c}} \mathrm{dm}^{-3}\right) ; \mathrm{CTCe}=0,9\left(\mathrm{cmol}_{\mathrm{c}} \mathrm{dm}^{-3}\right)$; argila $=260 \mathrm{~g} \mathrm{~kg}^{-1}$, silte $=159 \mathrm{~g} \mathrm{~kg}^{-1}$ e areia $=590 \mathrm{~g} \mathrm{~kg}^{-1}$ (EMBRAPA, 1999).

O delineamento experimental utilizado foi o de blocos casualizados em esquema fatorial ( $3 \mathrm{x} 4)$, com quatro repetições. O primeiro fator correspondeu as cultivares e o segundo as formas de aplicação do N, resultando em 12 tratamentos. A parcela experimental foi constituída de cinco fileiras de 4,0 $\mathrm{m}$ de comprimento com espaçamento entre linhas de $0,80 \mathrm{~m}$ e $0,20 \mathrm{~m}$ entre plantas. Para efeito de coleta de dados foram consideradas apenas as três linhas centrais, eliminando-se $0,5 \mathrm{~m}$ nas extremidades das fileiras, sendo a área útil 7,2 $\mathrm{m}^{2}$. 
Utilizaram-se três cultivares de girassol, selecionadas pelas características específicas de produção de óleo e por serem materiais promissores para o cultivo na região Norte, sendo: $\mathrm{C}_{1}$ - Agrobel 960 (Grão Negro) - híbrido triplo, ciclo de 90 a 118 dias, resistente ao acamamento, altura de $1,70 \mathrm{~m}$, população de 45.000 plantas ha $\mathrm{h}^{-1}$ e teor de óleo entre 42 a 48\%; C2 - Agrobel 962 (Grão Negro) - híbrido triplo, com ciclo de 120 dias, resistente ao acamamento, altura de $1,60 \mathrm{~m}$, população de 45.000 plantas ha ${ }^{-1}$ e o teor de óleo entre 43 a $50 \% ; \mathrm{C}_{3}$ - Embrapa 122/V2000 (Grão Estriado) - variedade, ciclo de 100 dias, altura de $1,55 \mathrm{~m}$, população entre $40.000 \mathrm{a}$ 45.000 plantas $\mathrm{ha}^{-1}$, o teor de óleo varia entre 40 a $44 \%$ (GIRASSÓIS..., 2007).

As formas de aplicação da dose recomendada de N, $60 \mathrm{~kg} \mathrm{ha}^{-1}$, tendo como fonte o sulfato de amônio, foram: $100 \%$ aos 20 dias após a semeadura (DAS) - (0-100-0-0); $30 \%$ na semeadura e $70 \%$ aos 20 DAS - (30-70-0-0); $30 \%$ na semeadura, $30 \%$ aos 20 DAS e $40 \%$ aos 40 DAS (30$30-40-0$ ) e $20 \%$ na semeadura, $30 \%$ aos 20 DAS, $30 \%$ aos 40 DAS e $20 \%$ aos 60 DAS (20-30-30-20). As adubações de coberturas com sulfato de amônio foram realizadas a lanço, na linha de cultivo a $20 \mathrm{~cm}$ do colo da planta, nos estágios $\mathrm{V}_{4}$ (plantas com quatro folhas e mais de $4 \mathrm{~cm}$ de comprimento), $\mathrm{V}_{10}$ (plantas com dez folhas com mais de 4 cm de comprimento) e $\mathrm{R}_{1}$ (aparecimento do botão floral) (SCHNEITER; MILLER, 1981).

O preparo do solo foi realizado com uma aração profunda $(30-40 \mathrm{~cm})$ seguida de duas gradagens. Para a correção do solo empregou-se $1 \mathrm{t} \mathrm{ha}^{-1}$ de calcário dolomítico com PRNT de $100 \%$ e a adubação de semeadura foi realizada manualmente aplicando-se $375 \mathrm{~kg} \mathrm{ha}^{-1}$ da fórmula 2-24-12 de NPK. A semeadura foi realizada com três sementes a cada $0,20 \mathrm{~m}$ de sulco. $\mathrm{O}$ desbaste foi realizado aos 20 dias após a emergência, quando se deixou apenas uma planta por cova numa população de 42.700 plantas ha-1 . Aos 20 DAS foi realizada uma cobertura na linha de cultivo a 20 cm do colo da planta com $80 \mathrm{~kg} \mathrm{ha}^{-1}$ de $\mathrm{K}_{2} \mathrm{O}$, utilizando-se como fonte o cloreto de potássio. Foi aplicado aos 50 DAS $107 \mathrm{~mL} \mathrm{ha}^{-1}$ de boro plus com $(11,5 \%$ de B).

Ao longo do cultivo foram realizadas três capinas e duas aplicações de inseticida organofosforado visando o controle de pragas, principalmente da vaquinha (Cerotoma arcuata OLIVIER). A manutenção da umidade da área foi feita por irrigação, microaspersão, monitorada por tensiômetros mantendo-se a umidade do solo próxima a $80 \%$ da capacidade de campo.

Em uma amostra de 10 plantas, selecionadas ao acaso dentro da área útil, foram avaliadas as seguintes variáveis: altura de plantas, tomando como medida a inserção do capítulo até o colo da planta, no florescimento pleno, $\mathrm{R}_{5.5}$ (SCHNEITER; MILLER, 1981); altura do capítulo, medida do nível do solo até a base do capítulo, no início da maturação, $\mathrm{R}_{9}$; diâmetro da haste, medindo-se com paquímetro a $5 \mathrm{~cm}$ do nível do solo, no final do florescimento pleno; diâmetro do capítulo, medindo-se 10 capítulos amostrados dentro da área útil, por ocasião da colheita.

A produção de aquênios foi avaliada na área útil de cada parcela, com a colheita manual dos capítulos, secagem em estufa, trilha mecânica, pesagem e determinação da umidade e posterior correção da umidade para $11 \%$ e assim determinou-se a produtividade de grãos por hectare.

Os dados foram submetidos a análise de variância e as médias dos tratamentos comparadas pelo teste de Tukey, a 5\% de probabilidade. As análises estatísticas foram realizadas utilizando-se o Sistema para Análises Estatísticas e Genéticas (SAEG) desenvolvido na Universidade Federal de Viçosa.

\section{Resultados e discussão}

As sementes das cultivares de girassol utilizadas no plantio apresentaram poder germinativo superior a $85 \%$. O estande de plantas manteve-se uniforme ao longo dos 15 dias iniciais, passando a apresentar diferenças no restante do ciclo em função das características genéticas intrínsecas de cada cultivar.

Observa-se na Tabela 1 que a interação entre os fatores cultivares e formas de aplicação do $\mathrm{N}$ não foi significativa para nenhuma das variáveis estudadas. Diante disso, passou-se a estudar o efeito isolado de cada fator. Verificou-se que as cultivares apresentaram diferenças significativas para a altura da planta e altura do capítulo. As formas de aplicação do $\mathrm{N}$ influenciaram de modo significativo todas as variáveis estudadas.

$\mathrm{Na}$ Tabela 2 pode-se observar que as plantas apresentaram alturas que variaram de 114,6 (Agrobel 962) a 122,9 cm (Agrobel 960), estando abaixo da faixa obtida por Smiderle et al. (2005). A altura da planta é um reflexo das condições nutricionais no período de alongamento do caule. A resposta diferencial das cultivares mostrou que a Agrobel 960 foi mais eficiente quanto às condições edafoclimáticas de seu cultivo.

A altura do capítulo variou de 63,4 (Agrobel 960) a 78,2 cm (Agrobel 962), encontrando-se dentro da faixa necessária a colheita mecanizada (TAB 2). A cultivar Agrobel 962 apresentou a menor altura da planta e maior altura de capítulo, o que sugere a possibilidade de seu cultivo em menores espaçamentos, contribuindo, com isso, no controle de plantas daninhas (AMABILE et al., 2003). As variações observadas na altura das plantas e do capítulo entre as cultivares não se refletiram nas variáveis ligadas a produção, diâmetro do capítulo e produtividade. 
Tabela 1 - Resumo da análise de variância das variáveis agronômicas de três cultivares de girassol submetidas a quatro formas de aplicação de $\mathrm{N}$

\begin{tabular}{ccccccc}
\hline \multirow{2}{*}{ FV } & \multirow{2}{*}{ GL } & \multicolumn{6}{c}{ Quadrado médio } \\
\cline { 3 - 7 } & & AP & AC & DC & DH & PR \\
\hline Bloco & 3 & $213,82^{\text {ns }}$ & $64,24^{\text {ns }}$ & $8,72^{* *}$ & $0,079^{*}$ & $10,77^{* *}$ \\
FN & 3 & $762,49^{* *}$ & $257,52^{* *}$ & $9,98^{* *}$ & $0,177^{* *}$ & $5,51^{* *}$ \\
CUL & 2 & $275,44^{*}$ & $898,5^{* *}$ & $1,38^{\text {ns }}$ & $0,006^{\text {ns }}$ & $0,148^{\text {ns }}$ \\
PN*CUL & 6 & $47,804^{\text {ns }}$ & $31,39^{\text {ns }}$ & $1,54^{\text {ns }}$ & $0,033^{\text {ns }}$ & $0,875^{\text {ns }}$ \\
Resíduo & 33 & 81,03 & 55,67 & 1,52 & 0,02 & $66.976,5$ \\
\hline CV $(\%)$ & & 7,56 & 10,44 & 9,15 & 13,24 & 15,79 \\
\hline
\end{tabular}

FV - Fontes de Variação; FN - Formas de aplicação de N; Cul - Cultivar; AC- Altura do capítulo; AP - Altura da planta; DC - Diâmetro do capítulo; DH - Diâmetro da haste; PR - Produtividade de aquênios; ${ }^{\text {ns }}$ - não significativo, ${ }^{*}$ - significativo a $5 \%{ }^{* *}$ - significativo a $1 \%$ de probabilidade

Tabela 2 - Médias estimadas das variáveis agronômicas para três cultivares de girassol submetidas a quatro formas de aplicação de $\mathrm{N}$

\begin{tabular}{|c|c|c|c|c|c|}
\hline Cultivares & AP & $\mathrm{AC}$ & $\mathrm{DC}$ & $\mathrm{DH}$ & PR \\
\hline & \multicolumn{2}{|c|}{----------------------(cm)------------------- } & \multicolumn{2}{|c|}{-------------------(mm)-----------------" } & $\left(\mathrm{kg} \mathrm{ha}^{-1}\right)$ \\
\hline Agrobel 960 & $122,9 \mathrm{a}$ & $63,4 \mathrm{~b}$ & 13,2 & 12,4 & 1.649 \\
\hline Agrobel 962 & $114,6 \mathrm{~b}$ & $78,2 \mathrm{a}$ & 13,8 & 12,3 & 1.657 \\
\hline Embrapa 122/V2000 & $119,5 \mathrm{ab}$ & $72,8 \mathrm{a}$ & 13,5 & 12,0 & 1.611 \\
\hline Média & - & - & 13,5 & 12,2 & 1.639 \\
\hline
\end{tabular}

AP - Altura da planta; AC - Altura do capítulo; DC - Diâmetro do capítulo; DH - Diâmetro da haste e PR - Produtividade de aquênios. Na coluna, médias seguidas da mesma letra, não diferem entre si pelo teste de Tukey a 5\% de probabilidade

O diâmetro da haste das cultivares, observado na Tabela 2, apresentou média de $12,2 \mathrm{~mm}$, sendo inferior aos observadas na literatura (BISCARO et al., 2008; CASTRO et al., 1999; SMIDERLE et al., 2005). É possível que esse baixo diâmetro esteja em conformidade com a baixa estatura das plantas em decorrência, por sua vez, da redução no ciclo. Apesar do baixo valor de diâmetro, não foi registrado acamamento ou quebra das plantas das três cultivares.

Durante a condução do experimento verificouse, ainda, que entre as cultivares estudadas a Embrapa 122/V2000 apresentou elevada desuniformidade quanto à altura, diâmetro da haste e diâmetro do capítulo. É possível que esse fato deva-se inicialmente a sua condição genética, por não se tratar de uma cultivar híbrida e ao vigor inicial das plântulas, que demonstrou ser inferior ao das demais. A baixa uniformidade verificada na cultivar Embrapa 122/V2000 pode limitar o uso da colheita mecanizada e o seu plantio em grandes áreas.

As cultivares apresentaram média de produtividade de $1.639 \mathrm{~kg} \mathrm{ha}^{-1}$ (TAB 2), sendo inferior a obtida por Smiderle et al. (2005) que foi de $2.717,98 \mathrm{~kg} \mathrm{ha}^{-1}$. Essa média encontra-se entre a faixa de 1.447 a 2.619,54 $\mathrm{kg} \mathrm{ha}^{-1}$, obtida por Porto et al. (2008), em estudo realizado no Brasil Central com cultivares de girassol em três anos agrícolas. Entretanto, para as condições do Distrito Federal esse valor está aquém dos rendimentos obtidos, que estão acima de $2.500 \mathrm{~kg} \mathrm{ha}^{-1}$ (FARIAS NETO et al., 2000). Para as condições edafoclimáticas do Rio Grande do Sul, Pires et al. (2007), estudando diferentes genótipos de girassol, encontraram produtividade média de $1.663 \mathrm{~kg} \mathrm{ha}{ }^{-1}$, semelhante ao obtido neste experimento. Os valores de produtividade obtidos indicam que as condições da savana de Roraima não afetaram negativamente a capacidade produtiva das cultivares, dada a época de cultivo. Os resultados demonstraram que não há superioridade dos híbridos sobre a variedade quanto ao ciclo e produtividade.

Conforme Porto et al. (2007) esses resultados indicam que o produtor pode cultivar qualquer uma das três cultivares em período de entressafra, mas que a melhoria das condições ambientais (maior adubação, adequação da época de plantio, melhor controle fitossanitário) poderá trazer maiores retornos econômicos, pois a produtividade obtida nas condições experimentais apresentou-se dentro 
da faixa de responsividade em período de alta temperatura e elevado requerimento hídrico.

Na Tabela 3 observa-se que para a altura de planta os tratamentos onde o $\mathrm{N}$ foi aplicado até 40 DAS não apresentaram diferenças significativas, determinando uma média de $122,73 \mathrm{~cm}$. O N em cobertura, até $40 \mathrm{DAS}$, foi importante para o crescimento das plantas, fazendo com que as mesmas tivessem um bom porte, não havendo acamamento, e facilitando o manejo e a colheita.

$\mathrm{O}$ parcelamento de $\mathrm{N}$ até 60 DAS mostrou-se inferior aos tratamentos onde o $\mathrm{N}$ foi fornecido a planta até 40 DAS, determinando redução de $14 \%$ na altura da planta, apresentando média de 107,70 cm. É possível que a última dose aplicada (60 DAS) tenha sido posterior ao período de alongamento do caule, dada a redução do ciclo observada para as três cultivares.

A cultivar Embrapa 122/V2000 apresentou ciclo de 81 dias, tendo entrado em plena floração aos 40 dias, quando o recomendado para cultivar em outros Estados onde foi indicada para cultivo, um ciclo de 100 dias e floração aos 53 dias (GIRASSÓIS..., 2007). O híbrido triplo AG-960 tem ciclo estimado entre 90 a 118 dias e o híbrido AG-962 tem ciclo de 120 dias, ambos foram colhidos aos 90 dias. O florescimento precoce e encurtamento do ciclo, para todas as cultivares, podem estar ligados a época de plantio. Resultados semelhantes na redução do ciclo foram observados por Smiderle et al. (2005) ao testar seis cultivares em condições de savana em Roraima.

A altura do capítulo variou de 65,60 a 76,67 cm em função das diferentes formas de aplicação do N (TAB. 3). A maior altura do capítulo foi obtida com a aplicação de $30 \%$ do N no plantio e o restante aos 20 DAS. Contudo, este tratamento só foi superior o de 20-30-30-20. A aplicação do $\mathrm{N}$ por ocasião do plantio e 20 dias após a semeadura demonstrou ser importante na determinação da altura do capítulo, proporcionando eficiência de $17 \%$ em relação ao tratamento 20-30-30-20. Por outro lado, a aplicação tardia do $\mathrm{N}$ não trouxe benefício para a altura do capítulo, indicando que há declínio na capacidade de absorção do $\mathrm{N}$ pela planta nessa fase de desenvolvimento.

Quanto ao diâmetro do capítulo observa-se, na Tabela3, que as formas de aplicação que disponibilizaram o $\mathrm{N}$ até 40 DAS proporcionaram os maiores ganhos para esta variável em relação ao tratamento onde o $\mathrm{N}$ foi aplicado até $60 \mathrm{DAS}$. O diâmetro do capítulo variou de 12,23 a 14,26 cm, situando-se dentro da variação de 6 a $50 \mathrm{~cm}$ estabelecida para a cultura, conforme Frank e Szabo (1989).

Os melhores tratamentos proporcionaram eficiência de $16 \%$ no diâmetro médio do capítulo, pelo manejo adequado da adubação nitrogenada (TAB. 3). Os valores para diâmetro do capítulo foi superior ao obtido por Biscaro et al. (2008), com valor máximo alcançado de $11,9 \mathrm{~cm}$ na dose de $44,9 \mathrm{~kg} \mathrm{ha}^{-1} \mathrm{de} \mathrm{N}$, parcelada em três vezes.

As formas de aplicação (30-70-0-0) e (30-3040-0) elevaram em $24 \%$ o diâmetro da haste, passando de $1,06 \mathrm{~cm}$ para $1,33 \mathrm{~cm}$, contribuindo para elevar a resistência das cultivares ao acamamento, permitindo facilitar seu manejo, tratos culturais e colheita. Os resultados observados na Tabela 3 , estão de acordo com os obtidos por Castro et al. (1999), que também verificaram variação no diâmetro da haste em função do método de aplicação de N.

Em relação à produtividade de aquênios foi evidente o seu aumento relativo em função da forma de aplicação do N, destacando-se o tratamento 30-70-0-0, cuja produtividade alcançada foi de $1.818,2 \mathrm{~kg} \mathrm{ha}^{-1}$, conferindo eficiência de 24\% em relação ao tratamento 20-30-30-20. É possível que a aplicação de parte do $\mathrm{N}$ tardiamente, $20 \%$

Tabela 3 - Médias das variáveis agronômicas em função de formas de aplicação de $\mathrm{N}$ em três cultivares de girassol cultivadas em Roraima

\begin{tabular}{|c|c|c|c|c|c|c|c|c|}
\hline \multicolumn{4}{|c|}{ Dias da Semeadura } & \multirow{3}{*}{$\begin{array}{c}\text { Altura da } \\
\text { Planta (cm) }\end{array}$} & \multirow{3}{*}{$\begin{array}{c}\text { Altura do } \\
\text { Capítulo (cm) }\end{array}$} & \multirow{3}{*}{$\begin{array}{l}\text { Diâmetro do } \\
\text { Capítulo (cm) }\end{array}$} & \multirow{3}{*}{$\begin{array}{l}\text { Diâmetro da } \\
\text { Haste (mm) }\end{array}$} & \multirow{3}{*}{$\begin{array}{l}\text { Produtividade } \\
\qquad\left(\mathrm{kg} \mathrm{ha}^{-1}\right)\end{array}$} \\
\hline 0 & 20 & 40 & 60 & & & & & \\
\hline \multicolumn{4}{|c|}{$\mathrm{N}$ aplicado $(\%)$} & & & & & \\
\hline 0 & 100 & 0 & 0 & $120,34 \mathrm{a}$ & $72,92 \mathrm{ab}$ & $13,38 \mathrm{ab}$ & $1,21 \mathrm{ab}$ & $1.512,7 \mathrm{bc}$ \\
\hline 30 & 70 & 0 & 0 & $126,43 \mathrm{a}$ & $76,67 \mathrm{a}$ & $14,26 \mathrm{a}$ & $1,33 \mathrm{a}$ & $1.818,2 \mathrm{a}$ \\
\hline 30 & 30 & 40 & 0 & $121,42 \mathrm{a}$ & $70,65 \mathrm{ab}$ & $14,04 \mathrm{a}$ & $1,29 \mathrm{a}$ & $1.759,0 \mathrm{ab}$ \\
\hline 20 & 30 & 30 & 20 & $107,70 \mathrm{~b}$ & $65,60 \mathrm{~b}$ & $12,23 \mathrm{~b}$ & $1,06 \mathrm{~b}$ & $1.466,2 \mathrm{c}$ \\
\hline \multicolumn{4}{|c|}{ Eficiêncial $^{1 /}(\%)$} & 14 & 17 & 16 & 24 & 24 \\
\hline
\end{tabular}

Na coluna, as médias seguidas da mesma letra, não diferem pelo teste de Tukey a $5 \%$ de probabilidade ${ }^{1 /}$ Eficiência $=\{[($ Melhor tratamento $\mathrm{x} 100) /($ Pior tratamento)]-100\} 
da recomendação aos 60 DAS, tenha provocado estresse nutricional na fase de formação e enchimento do capítulo, comprovando o efeito limitante do $\mathrm{N}$ na produção do girassol. De modo geral a produtividade obtida ficou dentro da faixa obtida por Smiderle et al. (2005).

Com exceção da altura da planta, o tratamento onde toda a cobertura do $\mathrm{N}$ foi aplicada aos 20 DAS (0-100-0-0) não se diferenciou estatisticamente do tratamento 20-30-30-20 para as demais variáveis estudadas. A aplicação de toda dose de $\mathrm{N}$ aos 20 DAS pode ter causado aumento da salinidade afetando negativamente o vigor das plantas e também saturado o complexo sortivo do solo, que apresentou baixa capacidade de troca de cátions, ficando parte do $\mathrm{N}$ susceptível a lixiviação e limitando a sua absorção na fase onde o crescimento da planta demanda de maior aporte de nutrientes, próximo à floração.

Bastos et al. (2008), estudando doses e formas de parcelamento de $\mathrm{N}$ para a produção de milho, no Cerrado do Meio-Norte do Brasil, concluíram que não há necessidade de se parcelar o adubo nitrogenado em mais de duas vezes, corroborando com os resultados obtidos nesse trabalho. A recomendação mais comum para a aplicação de $\mathrm{N}$ é parcelar a dose e fornecer o nutriente o mais próximo possível do estádio de desenvolvimento em que a planta necessite ou possa utilizá-lo. A principal razão é reduzir os riscos de perdas de $\mathrm{N}$ do solo especialmente por lixiviação, além de evitar efeitos salinos ou excesso de $\mathrm{NH}_{3}$ próximo das sementes.

As aplicações de doses de $\mathrm{N}$ parceladas, em duas ou três vezes, até 40 DAS, proporcionaram incrementos significativos em todas as variáveis analisadas, devido ao fato do $\mathrm{N}$ estar associado, dentre outras funções na planta, ao crescimento vegetativo (KARLEN et al., 1988). Por outro lado, o parcelamento de $\mathrm{N}$ até $60 \mathrm{DAS}$, reduz a disponibilidade desse nutriente na fase de maior demanda nutricional, entre a germinação e o florescimento, comprometendo o desenvolvimento radicular, com conseqüente efeito negativo no desenvolvimento da parte aérea (FANCELLI, 1997).

Constata-se pelos resultados que a utilização de girassol em áreas de savana apresenta-se como alternativa viável, uma vez que a produção das diferentes cultivares testadas apresentou média superior a $1.500 \mathrm{~kg} \mathrm{ha}^{-1}$, sendo considerada satisfatória para viabilizar a implantação da cultura. A forma de aplicação do $\mathrm{N}$ determina maior eficiência desse insumo, elevando os ganhos em produtividade da ordem de $24 \%$. Indica-se, portanto, para as condições de cultivo irrigado, que a dose de $\mathrm{N}$ recomendada, $60 \mathrm{~kg} \mathrm{ha}^{-1}$, seja aplicada $30 \%$ na semeadura e $70 \%$ aos 30 DAS.

\section{Conclusões}

1.Os híbridos Agrobel 960 e Agrobel 962 não apresentaram superioridade em relação à variedade Embrapa 122/V2000 quanto à produtividade;

2.A forma de aplicação do $\mathrm{N}$ (30-70-0-0) foi a que determinou os melhores resultados para as variáveis estudadas, mas a aplicação do $\mathrm{N}$ (30-30-40-0) proporcionou resultados comparáveis ao tratamento (30-70-0-0);

3. O tratamento onde o $\mathrm{N}$ foi aplicado na forma (20-30-3020) determinou redução no desempenho do girassol em todas as variáveis estudadas.

\section{Referências}

ACOSTA, J. F. Consumo hídrico do girassol irrigada na região da Chapada do Apodi - RN. Campina Grande, 2009. 56 f. Dissertação (Mestrado em Meteorologia) - Centro de Tecnologia e Recursos Naturais, Universidade Federal de campina Grande.

AMABILE, R. F.; GUIMARÃES, D. P.; FARIAS NETO, A. L. de. Análise de crescimento de girassol em Latossolo com diferentes níveis de saturação por bases no Cerrado. Pesquisa Agropecuária Brasileira, v. 38, n. 32, p. 219-224, 2003.

ARAÚJO, W. F. et al. Precipitação pluviométrica provável em Boa Vista, Estado de Roraima, Brasil. Revista Brasileira de Engenharia Agrícola e Ambiental, v. 05, n. 03, p. 563-567, 2001.

BASTOS, E. A. et al. Doses e formas de parcelamento de nitrogênio para a produção de milho sob plantio direto. Revista Ciência Agronômica, v. 39, n. 02, p. 275-280, 2008.

BISCARO, G. A. et al. Adubação nitrogenada em cobertura no girassol irrigado nas condições de Cassilândia-MS. Ciência e Agrotecnologia, v. 32, n. 05, p. 1366-1373, 2008.

CASTRO, C. de; BALLA, A.; CASTIGLIONI, V. B. R. Doses e métodos de aplicação de nitrogênio em girassol. Scientia Agricola, v. 56, n. 04, p. 827-833, 1999.

EMPRESA BRASILEIRA DE PESQUISA AGROPECUÁRIA. Centro Nacional de Pesquisa de Solos. Sistema Brasileiro de Classificação de Solos. Brasília, DF, 1999. 412 p.

FANCELLI, A. L. Cultura do milho: A importância da tecnologia. Informações Agronômicas, v. 01, n. 78. p. 4-6, 1997.

FOOD AND AGRICULTURE ORGANIZATION (FAO). (2008). The state of the food and agriculture 2008. Disponível em: <http://faostat.fao.orglsitel 340/default. aspx>. Acesso em: 20 jul. 2009.

FARIAS NETO, A. L. de et al. Avaliação de variedades de girassol nos Cerrados do Distrito Federal. Revista Ceres, v. 47, n. 273, p. 469-482, 2000.

FRANK, J.; SZABO, L. A. A naprafargo Helianthus annuus, L. Budapest: Akadémiai Kiadó, 1989.178 p. 
GIRASSÓIS Agrobel. Rio Verde, GO: Ceapar Cerrado Sementes, 2007. 2 p. Informativo distribuído pela Ceapar.

INSTITUTO BRASILEIRO DE GEOGRAFIA E ESTATÍSTICA. Levantamento sistemático da produção agrícola (LSPA). 2008. Disponível em: $<$ http://www.sidra.ibge. gov.br/bda/prevsaf $/$ default.asp?t $=2 \& \mathrm{z}=\mathrm{t} \& \mathrm{o}=23 \& \mathrm{ul}=1 \& \mathrm{u} 3=1 \& \mathrm{u}$ $4=1>$. Acesso em: 25 set. 2008.

KARLEN, D. L.; FLANERY, R. L.; SADLER, E. J. Aerial accumulation and partitioning of nutrients by corn. Agronomy Journal, v. 80, n. 02, p. 232-42, 1988.

PIRES, J. L. F. et al. Avaliação de genótipos de girassol na região do Planalto Médio do Rio Grande do Sul na safra 2005/2006. Passo Fundo: Embrapa Trigo, 2007. 15 p. (Embrapa Trigo. Boletim de Pesquisa e Desenvolvimento Online, 49).

PORTO, W. S.; CARVALHO, C. G. P. de; PINTO, R. J. B. Adaptabilidade e estabilidade como critérios para seleção de genótipos de girassol. Pesquisa Agropecuária Brasileira, v. 42, n. 04, p. 491-499, 2007.

PORTO, W. S. et al. Evaluation of sunflower cultivars for central Brazil. Scientia Agricola, v. 65, n. 02, p. 139-144, 2008.

PORTO, W. S. et al. Adaptabilidade e estabilidade de genótipos de girassol para a região subtropical do Brasil. Ciência Rural, v. 39, n. 09, 2009. Disponível em: <http://www.scielo.br/php? script $=$ sciarttext\&xtpid=S010384782009005 $000207 \quad \& \operatorname{lng}=$ pt\&nrm=iso>. Acesso em: 04 nov. 2009.

SCHNEITER, A. A.; MILLER, J. F. Description of sunflower growth stages. Crop Science, v. 21, n. 06, p. 901-903, 1981.

SILVA, E. C. et al. Doses e épocas de aplicação de nitrogênio na cultura do milho em plantio direto sobre Latossolo Vermelho. Revista Brasileira de Ciência do Solo, v. 29, n. 03, p. 353-362, 2005a.

SILVA, E. C. et al. Épocas e formas de aplicação de nitrogênio no milho sob plantio direto em solo de cerrado. Revista Brasileira de Ciência do Solo, v. 29, n. 05, p. 725-733, 2005 b.

SILVA, P. S. L.; SILVA, P. I. B. Parcelamento da adubação nitrogenada e rendimento de espigas verdes de milho. Horticultura Brasileira, v. 21, n. 01, p.150-153, 2003.

SMIDERLE, O. J.; MOURÃO JUNIOR., M.; GIANLUPPI, D. Avaliação de cultivares de girassol em savana de Roraima. Acta Amazônica, v. 35, n. 03, p. 331-336, 2005.

SOUZA, A. C. de. et al. Parcelamento e época de aplicação de nitrogênio e seus efeitos em características agronômicas do milho. Ciência Agrotécnica, v. 25, n. 02, p. 321-329, 2001. 